\title{
Fitness and Competitive Ability of Alternaria alternata Field Isolates with Resistance to SDHI, Qol, and MBC Fungicides
}

Zhen Fan, Department of Agricultural and Environmental Sciences, Clemson University, Clemson, SC 29634; Jing-Hui Yang, Zhenjiang Institute of Agricultural Sciences, Jiangsu, China; Fei Fan and Chao-Xi Luo, Department of Plant Protection, College of Plant Science and Technology and the Key Lab of Crop Disease Monitoring and Safety Control in Hubei Province, Huazhong Agricultural University, Wuhan, China; and Guido Schnabel, Department of Agricultural and Environmental Sciences, Clemson University

\begin{abstract}
Fan, Z., Yang, J.-H., Fan, F., Luo, C.-X., and Schnabel, G. 2015. Fitness and competitive ability of Alternaria alternata field isolates with resistance to SDHI, QoI, and MBC fungicides. Plant Dis. 99:1744-1750.

Field isolates of Alternaria alternata from peach were previously characterized for their sensitivity to succinate dehydrogenase inhibitor (SDHI) fungicides and the underlying molecular basis of resistance was determined. In the present study, we report that isolates resistant to the SDHI fungicide boscalid, regardless of genotype, were also resistant to pyraclostrobin and thiophanate-methyl. Resistance to pyraclostrobin was due to the G143A mutation in cytochrome $b$ and resistance to thiophanate-methyl was due to $167 \mathrm{Y}$ in $\beta$-tubulin. Representatives of the two most commonly isolated SDHI resistance genotypes, H277Y in $s d h$ subunit B and H134R in $s d h$ subunit C, as well as genotype $\mathrm{D} 123 \mathrm{E}$ in $s d h$ subunit $\mathrm{D}$, were selected for fitness evaluations. Genotypes H277Y and H134R suffered no fitness penalties

based on mycelial growth on potato dextrose agar, spore production in vitro, osmotic sensitivity, oxidative sensitivity, germination ability, or the ability to cause disease on peach fruit. Hypersensitivity to oxidative stress and weak sporulation was observed only in genotype D123E. No competitive advantage was detected for sensitive isolates over the course of five consecutive transfers on peach fruit when spores were mixed with genotypes $\mathrm{H} 277 \mathrm{Y}$ or H134R. Results suggest that, in the absence of fungicide pressure, A. alternata isolates resistant to methyl benzimidazole carbamate, quinone outside inhibitor, and SDHI fungicides carrying the H277Y mutation in SDHB and the H134R mutation in SDHC may effectively compete with the boscalid-sensitive populations.
\end{abstract}

Outbreaks of Alternaria rot caused by Alternaria alternata (Fr.) Keissl. have been increasing in some South Carolina peach orchards due to the emergence and selection of A. alternata strains resistant to succinate dehydrogenase inhibitor (SDHI) fungicides (Yang et al. 2015). Yield loss reached $60 \%$ in some late-season peach varieties (Yang et al. 2015). SDHI fungicides have been applied routinely in combination with quinone outside inhibitor (QoI) fungicides since the year 2000, mainly for the control of brown rot of peach, which is caused by Monilinia fructicola (G. Winter) Honey. Repeated annual applications appear to have unintentionally selected for resistance in this secondary plant pathogen. Resistance to SDHI in A. alternata from peach was based on mutations in $s d h$ gene sequences (Yang et al. 2015). Resistant isolates revealed H277Y/R/L mutations in the $s d h \mathrm{~B}$ gene, H134R and G79R mutations in the $s d h \mathrm{C}$ gene, and $\mathrm{D} 123 \mathrm{E}$ and D133R mutations in the $s d h \mathrm{D}$ gene (Avenot et al. 2008b, 2009; Yang et al. 2015). A. alternata isolates from California pistachio were resistant to SDHI fungicides in an earlier study, and the most prevalent genotypes were $\mathrm{H} 277 \mathrm{Y} / \mathrm{R}$ in the $s d h \mathrm{~B}$ gene and H134R in the $s d h$ C gene (Avenot et al. 2008b, 2009; Yang et al. 2015).

In addition to SDHI fungicides, methyl benzimidazole carbamate (MBC), demethylation inhibitor (DMI), and QoI fungicides have been used in rotation or mixture in peach orchards for summer disease control. To the best of our knowledge, A. alternata has reportedly been resistant to MBC fungicides (Eckert and Ogawa 1988; Thomidis et al. 2009) but the mechanism of resistance is unknown. Among single-site fungicides, only SDHI and QoI are registered

Corresponding author: G. Schnabel; E-mail: schnabe@clemson.edu

Technical Contribution Number 6347 of the Clemson University Experiment Station.

Accepted for publication 25 May 2015.

http://dx.doi.org/10.1094/PDIS-03-15-0354-RE

(C) 2015 The American Phytopathological Society and reported to be effective against $A$. alternata isolates. The rotation or mixture of the above chemical classes in southeastern peach orchards has already resulted in the selection of resistance in $\mathrm{M}$. fructicola, the causal organism of brown rot of stone fruit (Luo and Schnabel 2008; Ma et al. 2003b), and in Colletotrichum siamense, one of the causal organisms of peach anthracnose (Hu et al. 2015). For both pathogens, an accumulation of resistance to two or more fungicides was observed. Whether resistance to multiple fungicides has developed in A. alternata isolates from peach is not known.

For effective resistance management, knowledge about the molecular mechanism and fitness of genotypes is essential (Karaoglanidis et al. 2011). Fitness is defined as the survival and reproductive success of an allele, individual, or group (Pringle and Taylor 2002). If isolates carrying mutations in target genes have lower fitness than the boscalid-sensitive isolates, a decline in prevalence would be expected when removing the fungicide pressure. In contrast, if fitness cost is absent in resistant isolates, the resistant subpopulation would be expected to persist in the field even without fungicide selection pressure. Fitness of boscalid-resistant $A$. alternata isolates from pistachio was assessed previously but it is unknown what genotype or genotypes were included in the study (Avenot and Michailides 2007). An in-depth analysis of prevalent SDHI-resistant genotypes is needed to assess their fitness and competitiveness.

The objectives of this study were to (i) determine whether A. alternata isolates resistant to SDHI fungicides have accumulated additional resistance to thiophanate-methyl and pyraclostrobin, (ii) investigate the molecular mechanisms of this resistance, and (iii) conduct an in-depth analysis of key fitness components and competitiveness of resistant isolates.

\section{Material and Methods}

Origin, collection, and identification of isolates. The A. alternata isolates used in this study were first characterized in a previous study (Yang et al. 2015) for their sensitivity to four SDHI fungicides. In that study, details on origin, collection, and identification are reported. Briefly, isolates were collected in 2012 and 2013 from mature fruit of commercial late-season peach varieties. Single-spore 
isolates were obtained and identified to species level based on ribosomal DNA sequences (Yang et al. 2015).

For the present study, 12 isolates with different nucleotide mutations in the $s d h$ genes were selected to investigate fitness and competitiveness. Three sensitive isolates (Aa SE 12-17, Aa EY 12-1, and Aa RR 13-5) with no mutations in $s d h$ genes B, C, or D were included, as well as three isolates (Aa SE 12-10, Aa RR 13-28, and Aa SE 1213) with the $\mathrm{H} 277 \mathrm{Y}$ mutation in the $s d h \mathrm{~B}$ subunit, three isolates (Aa RR 13-26, Aa EY 12-6, and Aa RR 13-36) with the H134R mutation in the $s d h$ C subunit, and three isolates (Aa RR 13-21, Aa SE 12-14, and Aa RR 12) with the D123E mutation in the $s d h \mathrm{D}$ subunit. These four genotypes were selected because they were the most common genotypes found in our collection of isolates from South Carolina. Our collection had one isolate sensitive to pyraclostrobin; this isolate was not included in this study because of its comparably slow mycelial growth. All mutations in $s d h$ subunits conferred resistance to boscalid and penthiopyrad but mutation $\mathrm{H} 277 \mathrm{Y}$ also conferred resistance to fluxapyroxad and mutation H134R also conferred resistance to fluopyram and fluxapyroxad. Three sensitive isolates, three with mutation H277Y, and three with mutation H134R were selected to investigate competitiveness. Both mutations are associated with high resistance to boscalid. Isolates with mutation D123E had low to medium resistance to boscalid (Yang et al. 2015) and were excluded due to our focus on high resistance and to keep the number of isolates in experiments at a manageable level.

Sensitivity to thiophanate-methyl and pyraclostrobin. Mycelial growth tests were conducted to estimate sensitivity to thiophanatemethyl and pyraclostrobin. Commercial formulations of thiophanatemethyl (Topsin-M; Ceraxagri, King of Prussia, PA) and pyraclostrobin (Cabrio EG fungicide; BASF Corporation, Research Triangle Park, $\mathrm{NC}$ ) were dissolved in distilled water to obtain a stock solution of $10 \mathrm{mg} / \mathrm{ml}$. Salicylhydroxamic acid (SHAM) was dissolved in methanol at a concentration of $10 \mathrm{mg} / \mathrm{ml}$. SHAM is often used as an alternative oxidative pathway inhibitor to prevent fungus from overcoming toxicity of a QoI fungicide (Pasche et al. 2004). Fungicides were added to autoclaved yeast extract-bactopeptone-sodium acetate (YBA) cooled to $55^{\circ} \mathrm{C}$. Three final concentrations of 0 (control), 5 , and $100 \mu \mathrm{g} / \mathrm{ml}$ were used; at these discriminatory doses, sensitive isolates were expected to only grow in the controls. SHAM was amended to the YBA medium at $100 \mu \mathrm{g} / \mathrm{ml}$ in control and pyraclostrobinamended medium. For each isolate, three replicate plates were prepared. Isolates with low resistance to thiophanate-methyl or azoxystrobin were expected to grow on a medium amended with $5 \mu \mathrm{g} / \mathrm{ml}$ but not on a medium amended with $100 \mu \mathrm{g} / \mathrm{ml}$. Highly resistant isolates were expected to grow on medium amended with the fungicides at $100 \mu \mathrm{g} / \mathrm{ml}$.

Molecular basis of resistance. Genomic DNA of the 12 A. alternata isolates chosen for this experiment (Aa RR 12, Aa RR 13-34, Aa RR 13-35, Aa RR 13-36, Aa SE 12-4, Aa SE 12-5, Aa SE 12-17, Aa EY 12-1, Aa RY 12-2, and Aa EY 12-5) was extracted using the MasterPure Yeast DNA Purification Kit (Epicentre Biotechnologies, Madison, WI). These isolates represented different resistance phenotypes and had different geographical origins (Yang et al. 2015). Pyraclostrobin-resistant isolates were from Ridge Spring, Monetta, and Chesnee in South Carolina. The sensitive isolate (Aa SE 12-3) was from Monetta. The cytochrome b (cyt b) gene fragment containing amino acid 143 was amplified and sequenced with primer pair cytb2f (CTATGGATCTTACAGAGCAC) and CBR2 (AACAATATCTTGTCCAATTCATGG) (Ma et al. 2003a; Vega et al. 2012). Polymerase chain reaction (PCR) reactions were performed in $50-\mu \mathrm{l}$ volumes containing $50 \mathrm{ng}$ of DNA, ThermoPol Buffer (50 mM KCL, $1.5 \mathrm{mM} \mathrm{MgCl}_{2}$, and $10 \mathrm{mM}$ Tris-HCL [pH 9.0]), dNTPs at $0.2 \mathrm{mM}$ each (New England BioLabs, Inc., Beverly, MA), primers at $0.2 \mu \mathrm{m}$ each, and $1 \mathrm{U}$ of Taq DNA polymerase (New England Biolabs, Inc.). PCR was carried out in a MyCycler Thermocycler (Bio-Rad Laboratories, Hercules, CA) with an initial preheat for $3 \mathrm{~min}$ at $95^{\circ} \mathrm{C}$; followed by 34 cycles of denaturation at $94^{\circ} \mathrm{C}$ for $40 \mathrm{~s}$, annealing at $50^{\circ} \mathrm{C}$ for $50 \mathrm{~s}$, and extension at $72^{\circ} \mathrm{C}$ for $1 \mathrm{~min}$; and terminated with a final extension at $72^{\circ} \mathrm{C}$ for $10 \mathrm{~min}$.
Primer pair btullf (GTGCCGTCCTCATCGATCTC) and btu2r (AGTTGGGACAGCCA-TCATGT) was designed based on the National Center for Biotechnology Information (NCBI) submitted sequence (NCBI accession number 325514225) to amplify the $\beta$-tubulin gene. Two isolates (Aa EY 12-5 and Aa RR 13-27) resistant to thiophanate-methyl were randomly chosen for sequencing. PCR reactions were performed as described above, except the annealing temperature was increased to $55^{\circ} \mathrm{C}$. PCR products were purified using ExoSAP-IT reagent (Affymetrix, Inc., Cleveland, $\mathrm{OH})$ prior to sequencing at the Clemson University Genomics Institute, Clemson, SC. The sequences were analyzed using BLASTbased algorithms. Both BLASTn and BLASTTx were performed to detect and annotate the nucleotide and protein sequences. Alignment of nucleotide and protein sequences was conducted using DNASTAR sequence analysis software (DNASTAR Inc., Madison, WI).

Fitness components. The following fitness components were determined for boscalid-resistant and boscalid-sensitive isolates: mycelial growth on potato dextrose agar (PDA), spore production in vitro, osmotic sensitivity, oxidative sensitivity, germination ability, and disease severity. All experiments were repeated once.

Mycelial growth on PDA. Mycelium plugs of each isolate were transferred from 4-day-old PDA plates to the center of fresh PDA plates for growth measurement. The plates were incubated at $25^{\circ} \mathrm{C}$ under continuous light. The colony diameter of each isolate was determined 3, 5, 7, and 10 days after inoculation. For each isolate, three plates were prepared.

Spore production in vitro. Isolates were cultured on PDA, V8 juice agar, and canned peach halves to determine sporulation in vitro. For PDA and V8 juice agar plates, mycelial plugs of each isolate were transferred to the center of the plates and incubated at $25^{\circ} \mathrm{C}$ under continuous light for 14 days. We then added $5 \mathrm{ml}$ of distilled water to each plate, dislodged the conidia with a cotton swab, and filtered the suspension through double-layered cheesecloth. Three plates were used for each isolate. Peach halves (from cans using light syrup) were placed in 400-ml Magenta boxes (one peach half per Magenta box), pit side facing down. Inoculation was conducted by pipetting $100 \mu \mathrm{l}$ of a conidia suspension $\left(10^{5} / \mathrm{ml}\right)$ to the top of each peach half. Magenta boxes were covered with a lid, sealed with Parafilm, and incubated at $25^{\circ} \mathrm{C}$ under continuous light for 7 days. The mycelia mass was then harvested, placed in a 50-ml tube, and suspended in $10 \mathrm{ml}$ of sterile distilled water. After vortexing for $20 \mathrm{~s}$, the conidial suspension was filtered through a double layer of cheesecloth. Two boxes were prepared for each isolate. The spore concentration in the suspension was measured with the aid of a hemacytometer and expressed as number of conidia per milliliter water. Two peach halves were prepared for each isolate. Two droplets were counted for each plate or box.

Osmotic sensitivity. Osmotic sensitivity was determined by comparing the growth of isolates on PDA, with growth on PDAamended with 2 and $4 \% \mathrm{NaCl}$. Colony diameters were measured after 5 days at $25^{\circ} \mathrm{C}$ under continuous light. Three replicate plates were prepared for each isolate.

Oxidative sensitivity. Paraquat was used as an indicator of oxidative stress (Avenot et al. 2009). PDA was amended with a commercial formulation of paraquat dichloride (Gramoxone; Syngenta Crop Protection, Greensboro, NC) to a final concentration of 0,90 , and $300 \mu \mathrm{g} / \mathrm{ml}$. Colony diameters were measured after 5 days at $25^{\circ} \mathrm{C}$ under continuous light. For each isolate, three replicate plates were prepared.

Germination ability. A 50-ml spore suspensions of each isolate was harvested from V8 juice agar plates and spread onto water agar plates. The inoculated plates were incubated at $22^{\circ} \mathrm{C}$ for $18 \mathrm{~h}$; then, the percentage of germinated spores per 100 conidia was recorded. A conidium was considered as germinated when the germ tube was longer than twice the length of the conidium. Three replicate plates were prepared for each isolate.

Disease severity. The mature peach fruit 'Redglobe' was harvested on 2 July 2014 and stored at $4^{\circ} \mathrm{C}$ for no more than 2 weeks. Peach fruit were adjusted to room temperature overnight before inoculation, 
then washed with soap, immersed in $1 \%$ bleach for $1 \mathrm{~min}$, and rinsed with water to remove the bleach residue. Wetted paper towels were placed on the bottom of a carbon-fiber tray containing 18 perforated pockets. Fruit were placed on 4-cm-diameter plastic rings in the pockets of the tray. After fruit were air dried, three plugs were removed with a cork borer from each fruit at three equidistant locations. Three mycelia plugs of the same size from the margin of 5-day-old PDA were placed on removed sites (Chen et al. 2013a). There were three replicates per isolate and three fruit per replicate. After inoculation, the trays were wrapped by plastic bags to keep the relative humidity high and incubated at $25^{\circ} \mathrm{C}$ for 6 days. Lesion diameters were recorded after 6 days.

Stability of resistance to SDHI fungicides. The $50 \%$ effective concentration $\left(\mathrm{EC}_{50}\right)$ values for boscalid, fluopyram, penthiopyrad, and fluxapyroxad were determined on YBA plates prior to and after transfers. The concentrations of boscalid, fluxapyroxad, and penthiopyrad were $0,0.01,0.03,0.1,0.3,1,3,10,30$, and $100 \mu \mathrm{g} / \mathrm{ml}$ and the concentrations for fluopyram were $0,0.03,0.1,0.3,1,3,10,30$, and $100 \mu \mathrm{g} / \mathrm{ml}$. In total, 10 transfers were conducted. Three replicate plates were prepared for each isolate and the experiment was repeated once.

Competitiveness of isolates with different genotypes. We assessed the competitive ability between boscalid-resistant and boscalidsensitive genotypes. A spore suspension of each resistant genotype was obtained from PDA plates as described above and mixed with a suspension of the sensitive phenotype at an initial ratio of 1:1 (H277Y:S; H134R:S). The final concentration of the initial conidia suspension was $3 \times 10^{4}$ spores $/ \mathrm{ml}$. Each genotype was represented by an equally proportioned $(1: 1: 1)$ suspension of spores of the three isolates with the same genotype. For example, H277Y was represented by a spore suspension of the resistant isolates Aa SE 12-10, Aa RR 13-28, and Aa SE 12-13 in equal proportions. This spore suspension was then mixed at a ratio of $1: 1$ with the spore suspension of equal proportions of the sensitive isolates Aa SE 12-17, Aa EY 12-1, and Aa RR 13-5. Control suspensions of each genotype were mixed with water to achieve the same dilution. Canned peach halves were inoculated as described above. Conidia from each fruit were harvested every 7 days and resuspended in $10 \mathrm{ml}$ of water. A total of $100 \mu l$ of the conidia suspension was used to inoculate a new peach half. Three peach halves were inoculated for every mixture in each transfer. The experiment was conducted three times and, each time, terminated after five transfers. The spore concentrations were determined at the end of each cycle with the aid of a hemacytometer and expressed as number of conidia per milliliter of water. The percentage of spores resistant to boscalid in the spore suspension was calculated at the end of each cycle. A total of $400 \mu \mathrm{l}$ of the spore suspension from each peach half was spread with an inoculation loop on two YBA plates $(200 \mu l$ per plate) amended with boscalid at $30 \mu \mathrm{g} / \mathrm{ml}$. Plates were incubated for $16 \mathrm{~h}$ at $22^{\circ} \mathrm{C}$ and germination of 100 spores/plate was examined under a microscope. A conidium was considered germinated when the germ tube was longer than twice the length of the conidium. At that dose, resistant isolates germinated and formed a germ tube but spores of sensitive isolates were inhibited.

Data analysis. In the experiments determining stability of resistance, $\mathrm{EC}_{50}$ values were calculated by regression analysis using dose-response curves. For experiments involving fitness components, data for three isolates of the same genotype were pooled. Brown-Forsythe tests were conducted for each fitness component to ensure homogeneity between experiments. Mean values of each genotype group were compared using a least significant difference test at $P=0.05$. For the competitive ability study, parameters of ratio of resistant spores, transfer, experiment, and transfer-experiment were fitted in a general linear model. Experiment and transfer-experiment were set as random effects. ANOVA was conducted to test the significance of transfers. All statistical analyses were performed with JMP software (version 10; SAS, Cary, NC).

\section{Results}

Sensitivity to thiophanate-methyl and pyroclostrobin. The sensitivity of 63 A. alternata isolates from South Carolina to thiophanatemethyl and pyraclostrobin was determined. Relative growth with thiophanate-methyl at $5 \mu \mathrm{g} / \mathrm{ml}$ ranged from 80.4 to $114.3 \%$. Even at $100 \mu \mathrm{g} / \mathrm{ml}$, none of the isolates were completely arrested in growth, and relative growth ranged from 64.5 to $123.8 \%$ (Fig. 1). These data indicated that all isolates were resistant to thiophanate-methyl. For all but one isolate, relative growth with pyraclostrobin at 5 and $100 \mu \mathrm{g} / \mathrm{ml}$ ranged from 51.6 to $95.2 \%$ and from 28.3 to $65.6 \%$, respectively, indicating that most isolates were resistant to this fungicide. One isolate was pyraclostrobin sensitive, with relative growth of 12.5 and $0 \%$ at 5 and $100 \mu \mathrm{g} / \mathrm{ml}$, respectively (Fig. 1).

Nucleotide sequence analysis of the cyt $\boldsymbol{b}$ and $\beta$-tubulin genes. The sensitivity to SDHI fungicides and underlying molecular basis of the isolates used in this study was determined previously (Yang et al. 2015) but molecular mechanisms of resistance to QoI fungicides and MBC fungicides were unknown. A single DNA fragment of the $c y t$
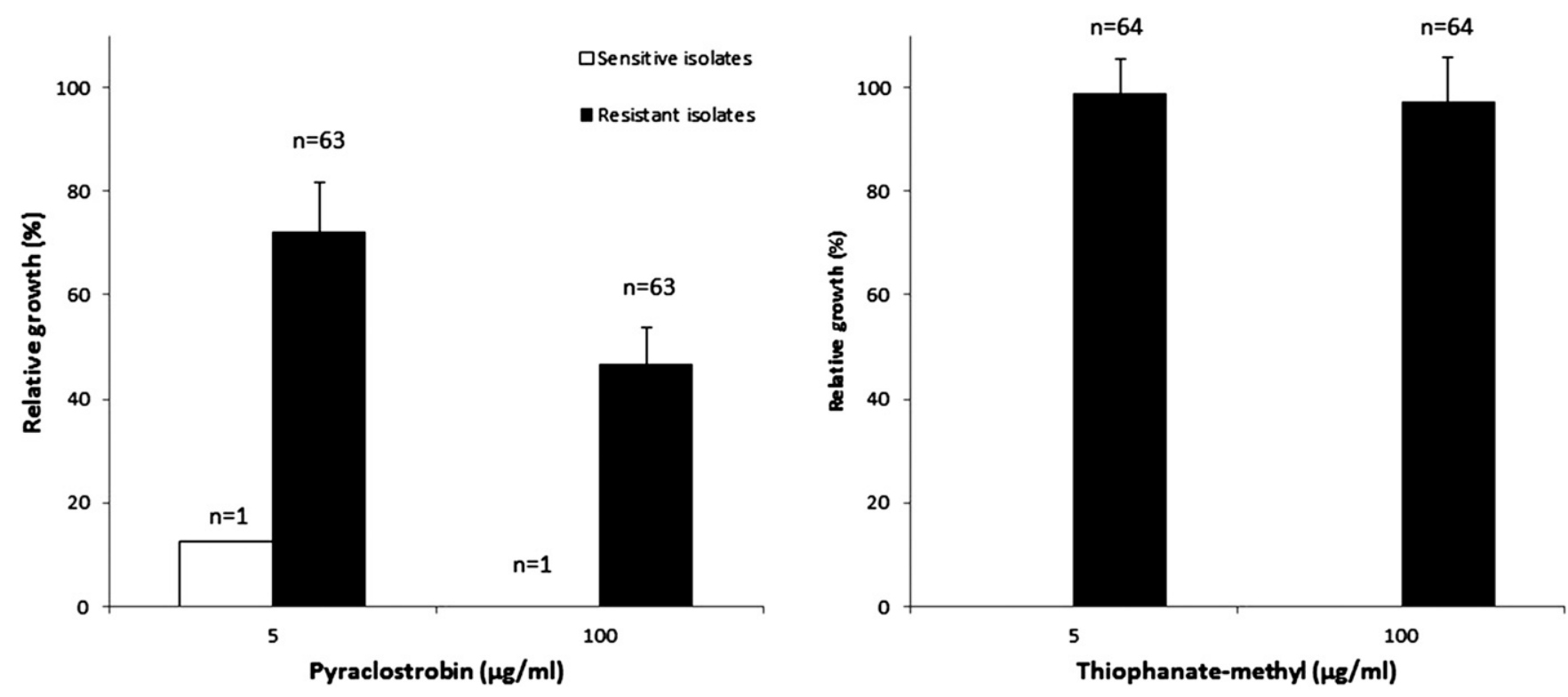

Fig. 1. Relative growth of 64 Alternaria alternata isolates on agar plates containing pyraclostrobin or thiophanate-methyl at 5 or $100 \mu \mathrm{g} / \mathrm{ml}$. Error bars represent standard deviations. 
$b$ gene, $182 \mathrm{bp}$ in length, was amplified and sequenced from all 12 isolates with primer pair cytb2f and CBR2. The nucleotide sequence matched the $c y t b$ gene from A. alternata (GenBank accession number AY263408.1). Comparison of the partial $c y t b$ gene sequence of the pyraclostrobin-sensitive and the 11 remaining pyroclostrobin-resistant isolates collected from different locations revealed that resistant isolates had a single point mutation at position 428 that changed GGT into GCT. This mutation caused an amino acid change of glycine to alanine at codon 143 of the $c y t$ $b$ gene (G143A).

A single DNA fragment of $729 \mathrm{bp}$ in length from two randomly picked, thiophanate-methyl-resistant isolates was amplified and sequenced with primer pair btullf and btu2r. The two sequences (available in GenBank, accessions KP640615 and KP640616) aligned perfectly with 25 other A. alternata $\beta$-tubulin gene sequences from GenBank and all sequences revealed the amino acid tyrosine at codon position 167 . The F167Y mutation in the $\beta$-tubulin gene was confirmed to confer high resistance to benzimidazole compounds in other organisms such as Saccharomyces cerevisiae, Penicillium expansum, and Gibberella zeae (Baraldi et al. 2003; Li et al. 1996; Qiu et al. 2011). Our data indicated that this mutation is likely the reason that A. alternata is resistant to thiophanate-methyl.
Fitness components. Mycelial growth. Isolates with mutation $\mathrm{D} 123 \mathrm{E}$ in $s d h \mathrm{D}$ grew more rapidly after $3,5,7$, and 10 days of incubation with mean values of $29.9,51.3,67.9$, and $80.7 \mathrm{~mm}$, respectively. Growth of boscalid-sensitive isolates and isolates with the $\mathrm{H} 134 \mathrm{R}$ or the $\mathrm{H} 277 \mathrm{Y}$ mutation in $s d h \mathrm{C}$ and $s d h \mathrm{~B}$, respectively, was not significantly different from each other (Fig. 2).

Spore production in vitro. All genotypes produced spores on the three different substrates (including peach) but there were substratespecific responses. The two independent experiments for each substrate were merged after verifying homogeneity of variance $(P=0.07, P=$ 0.82 , and $P=0.50$ for $\mathrm{V} 8$ juice agar, PDA, and peach, respectively). The sporulation ability of genotypes $\mathrm{H} 277 \mathrm{Y}$ and H134R were similar and both genotypes outperformed D123E regardless of the substrate. Boscalid-sensitive isolates' sporulation was similar to genotype $\mathrm{H} 277 \mathrm{Y}$ on two substrates but produced significantly more spores than all other genotypes on PDA $(P<0.001)$. Sporulation was greatest for all genotypes on V8 juice agar, with mean values of $32.9 \times 10^{4}$ spores $/ \mathrm{ml}$ compared with $3.5 \times 10^{4}$ and $13.8 \times 10^{4}$ spores $/ \mathrm{ml}$ for peach and PDA, respectively (Table 1).

Osmotic sensitivity. Osmotic sensitivity was assessed on 2 and $4 \%$ $\mathrm{NaCl}$-amended PDA. The two independent experiments were merged after verifying homogeneity of variance for 2 and $4 \% \mathrm{NaCl}(P=0.64$ and $P=0.88$, respectively). No significant difference in mycelial

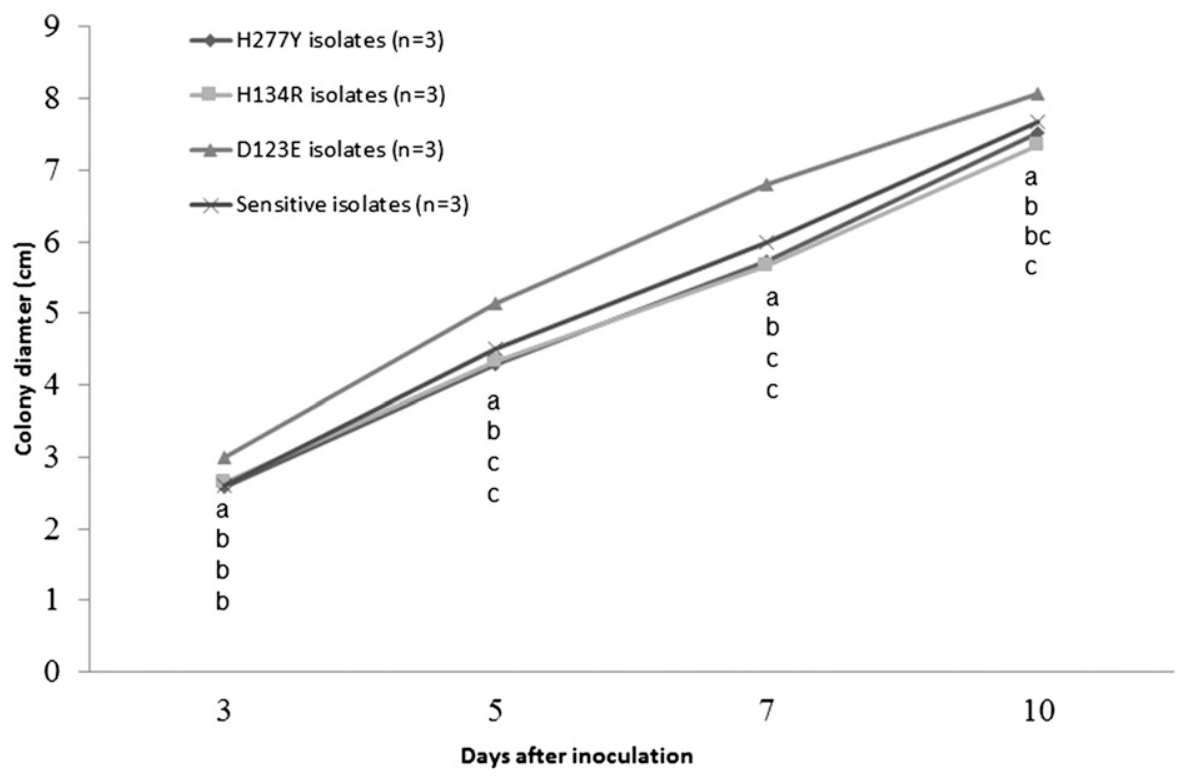

Fig. 2. Mycelial growth on potato dextrose agar plates after 3, 5, 7, and 10 days of incubation. Letters under data points are in order of isolate symbols. The same letters indicate no significant difference. Least significant difference tests were conducted at $P=0.05$.

Table 1. Sporulation, osmotic stress, oxidative stress, disease severity on detached fruit, and germination for pooled Alternaria alternata isolates carrying different mutations in the succinate dehydrogenase $(\mathrm{SDH})$ genes $^{\mathrm{x}}$

\begin{tabular}{|c|c|c|c|c|c|c|c|c|c|c|}
\hline \multirow[b]{3}{*}{ Genotype $^{y}$} & \multirow[b]{3}{*}{$N^{\mathbf{z}}$} & & & & \multicolumn{4}{|c|}{ Relative growth (\%) } & \multirow{3}{*}{$\begin{array}{l}\text { Mean lesion diameter } \\
\text { on peach }(\mathbf{c m})\end{array}$} & \multirow[b]{3}{*}{ Germination $(\%)$} \\
\hline & & \multicolumn{3}{|c|}{ Sporulation $\left(\times 10^{4}\right.$ spores $\left./ \mathrm{ml}\right)$} & \multicolumn{2}{|c|}{ PDA + NaCl } & \multicolumn{2}{|c|}{ PDA + Paraquat } & & \\
\hline & & V8 & Peach & PDA & $2 \%$ & $4 \%$ & $90 \mu \mathrm{g} / \mathrm{ml}$ & $300 \mu \mathrm{g} / \mathrm{ml}$ & & \\
\hline $\mathrm{H} 277 \mathrm{Y}$ & 3 & $38.6 \mathrm{a}$ & $4.8 \mathrm{a}$ & $12.1 \mathrm{~b}$ & $68.1 \mathrm{a}$ & $58.6 \mathrm{a}$ & $103.2 \mathrm{a}$ & $74.6 \mathrm{a}$ & $1.39 \mathrm{a}$ & $98.7 \mathrm{ab}$ \\
\hline H134R & 3 & $40.1 \mathrm{a}$ & $4.9 \mathrm{a}$ & $15.5 \mathrm{~b}$ & $66.5 \mathrm{a}$ & $53.3 \mathrm{a}$ & 87.7 be & $60.3 \mathrm{ab}$ & $1.13 \mathrm{~b}$ & $97.4 \mathrm{~b}$ \\
\hline D123E & 3 & $13.7 \mathrm{~b}$ & $1.2 \mathrm{~b}$ & $2.9 \mathrm{c}$ & $59.2 \mathrm{a}$ & $48.5 \mathrm{a}$ & $79.0 \mathrm{c}$ & $48.6 \mathrm{~b}$ & $1.15 \mathrm{~b}$ & $97.8 \mathrm{ab}$ \\
\hline No mutation & 3 & $34.3 \mathrm{a}$ & $3 a b$ & $25.3 \mathrm{a}$ & $60.6 \mathrm{a}$ & $47.6 \mathrm{a}$ & $92.1 \mathrm{~b}$ & $60.5 \mathrm{ab}$ & $1.13 \mathrm{~b}$ & $99.3 \mathrm{a}$ \\
\hline
\end{tabular}

$\times$ PDA $=$ potato dextrose agar. Least significant difference tests were conducted at $P=0.05$. Values next to the same letters within columns are not significantly different.

${ }^{y}$ Data of three isolates with the same mutation in the SDH subunit were pooled. Mutation H277Y was represented by isolates AaSE12-10, AaRR13-28, and AaSE12-13; mutation H134R was represented by isolates AaRR13-26, AaEY12-6, and AaRR13-36; mutation D123E was represented by isolates AaRR13-21, AaSE12-14, and AaRR12; and the wild type was represented by sensitive isolates AaSE12-17, AaEY12-1, and AaRR13-5.

${ }^{z}$ Number of isolates. 
growth was observed between genotypes for both concentrations $(P=$ 0.55 and $P=0.55$, respectively; Table 1 ).

Oxidative sensitivity. Oxidative stress was assessed on paraquatamended PDA. Data from the two independent experiments were merged after verifying homogeneity of variance for 90 - and 300$\mu \mathrm{g} / \mathrm{ml}$ concentrations of paraquat $(P=0.78$ and $P=0.22$, respectively). At the lower concentration of paraquat, the H277Y genotype grew the fastest $(P<0.001)$ among all the genotypes, and genotype D123E was significantly impaired compared with the boscalidsensitive isolates $(P=0.01)$. At the higher dose, the same trend was observed but significant differences were only observed between the D123E genotype and the boscalid-sensitive isolates $(P=0.02$; Table 1).

Germination rate. Although the Brown-Forsythe test showed that variances between the two experiments were not equal, the data were combined after careful consideration due to the visual homogeny of the results. The germination rates of all genotypes ranged between 97.4 and 99.3, and there was no significant difference among genotypes $(P=0.12$; Table 1$)$.

Disease severity. Disease severity was assessed on peach fruit. The two experiments were merged after verifying homogeneity of variance $(P=0.17)$. The H277Y genotype produced slight but significantly larger lesions than all other genotypes $(P=0.01$; Table 1$)$.

Stability of resistance to SDHI fungicides. After 10 transfers on nonamended PDA, resistance to penthiopyrad, boscalid, and fluxapyroxad remained stable for all resistant genotypes. Interestingly, a slight but significant increase in sensitivity to fluopyram was observed for the H277Y, H134R, and boscalid-sensitive isolate genotypes (Fig. 3).

Competitiveness of isolates with different genotypes. During the study, all genotypes were transferred individually (in addition to the mixtures) and the viability of their inoculum was confirmed in the absence of competition with other genotypes. All genotype controls sporulated consistently on canned peach throughout the study, indicating no detectable loss of saprophytic ability (data not shown). Regarding the experimental mixtures, no genotype was outcompeted over the course of this study. A dynamic equilibrium of spores from both genotypes was observed for both mixtures (H277Y:S and H134R:S-H277Y was represented by a spore suspension of the resistant isolates Aa SE 12-10, Aa RR 13-28, and Aa SE 12-13 in equal proportions; $S$ was represented by a spore suspension of the sensitive isolates Aa SE 12-17, Aa EY 12-1, and Aa RR 13-5 in equal proportions; and H134R was represented by a spore suspension of the resistant isolates Aa RR 13-26, Aa EY 12-6, and Aa RR 13-36 in equal proportions) over the course of five generations. A general mixed linear model analysis revealed that transfers were not a significant factor in both mixture types $(P=0.8$ and $P=0.08$, respectively). Spore production of the H134R genotype initially increased over the boscalid-sensitive isolates but then stabilized at about a $60 \%$ prevalence. Spore production of the H277Y genotype, however, initially decreased compared with the boscalid-sensitive isolates and then stabilized at about a $30 \%$ prevalence (Fig. 4).

\section{Discussion}

Resistance to multiple fungicides was confirmed in A. alternata isolates from peach characterized previously for their sensitivity to SDHI fungicides. The lack of efficacy of thiophanate-methyl and other thiophanates against $A$. alternata was noted as early as the 1970s (Eckert and Ogawa 1988; Thomidis et al. 2009). Therefore, it is possible that A. alternata in North America had been resistant to thiophanate-methyl even prior to its introduction in the early 1970s. Regardless, this study shows that the fungus had sufficiently diversified and generated genotypes with resistance to QoI and SDHI fungicides. QoI fungicides were introduced as solo products in 1998
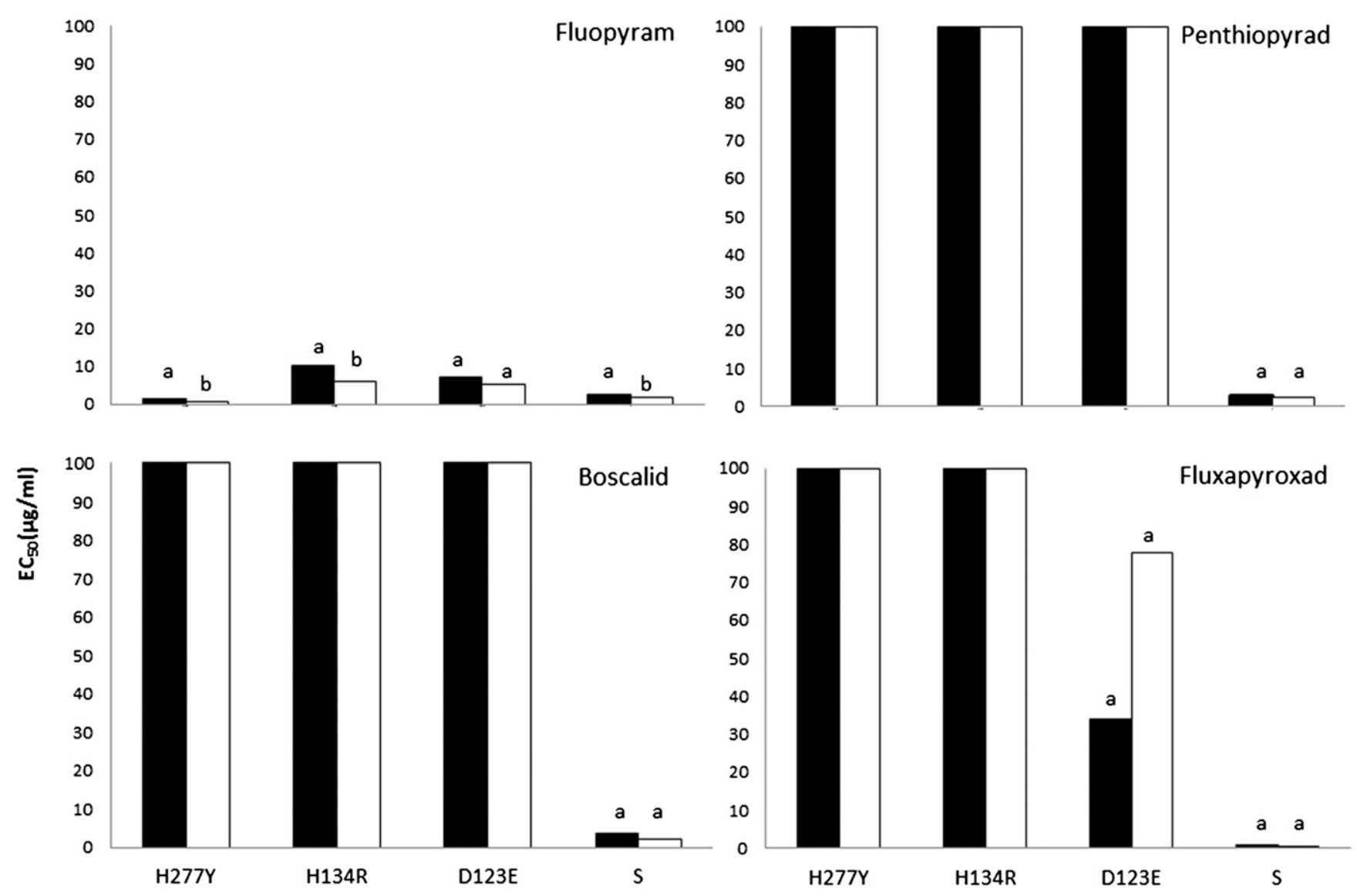

Fig. 3. The $50 \%$ effective concentration $\left(E_{50}\right)$ values for succinate dehydrogenase inhibitor fungicides before (black bars) and after (white bars) 10 consecutive transfers on potato dextrose agar (PDA) medium. Mycelial plugs were transferred to a new PDA plate every 6 days. Data of three isolates with the same mutation were pooled. The same letters for a pair of bars indicate no significant difference $(P=0.05)$. 
and then sold largely in a mixture with SDHI fungicides since 2002. Since then, the combination has been used routinely, several times per year in South Carolina peach orchards. This is the first report of resistance to QoI and SDHI fungicides in A. alternata of peach on the east coast, indicating that selection of resistance to both fungicides at a level of economic relevance took little more than 10 years. In contrast, $A$. alternata resistant to pyraclostrobin and boscalid was found in pistachio orchards after only 2 years of application of the boscalid-pyraclostrobin mixture (Avenot et al. 2008a). This more rapid emergence and selection of resistance may be a result of higher disease incidence and inoculum availability for selection; A. alternata is a major pathogen of pistachio but is generally of minor concern in peach orchards. Resistance to MBC, QoI, and SDHI fungicides in the same field isolate has also been reported in Botrytis cinerea from the United States and Europe (Fernández-Ortuño et al. 2012; Weber 2011). Dual resistance to pyraclostrobin and boscalid was found in 7 of 59 A. alternata field isolates from California pistachio with a history of boscalid and pyraclostrobin treatments. Although it is not specifically stated by the authors, it is likely that the isolates were also resistant to thiophanate-methyl based on the above-mentioned inherent resistance trait to thiophanate fungicides (Avenot et al. 2008a). In our study, the same resistance profile was detected in A. alternata field isolates from Southeast peach orchards with a much higher prevalence: 57 of 64 isolates with resistance to all three fungicides.

Tree fruit pathogens appear to be developing resistance to multiple fungicides at a fast pace. This may be due, in part, to the rotation and mixture practices of products belonging to different chemical classes of fungicides, the perennial nature of the host allowing continued selection pressure on its pathogen population, and the frequent application of fungicides needed for sustained crop production. For example, field isolates of Venturia inaequalis, the causal agent of apple scab, were found to be resistant to dodine, kresoxim-methyl, myclobutanil, and thiophanate-methyl (Chapman et al. 2011); and dodine, benzimidazoles, and DMI fungicides (Köller and Wilcox 2001). Under southeastern conditions, fungal pathogens thrive and A. alternata is now the third confirmed pathogen of peach in South Carolina to develop resistance to multiple fungicides. Field isolates of $M$. fructicola, the causal organism of peach brown rot, were reported to be resistant to the DMI propiconazole, MBC, and thiophanatemethyl (Chen et al. 2013b), as well as to propiconazole and the SDHI fungicide boscalid (Chen et al. 2013a). More recently, field isolates of $C$. siamense, causing anthracnose fruit rot on peach, were found to be resistant to thiophanate-methyl and azoxystrobin ( $\mathrm{Hu}$ et al. 2015). The observed acquisition of multiple resistances in field strains of peach pathogens is in line with selection pressure due to rotation or mixture of DMI, MBC, QoI, and SDHI fungicides for peach disease control.

The mechanisms of resistance to azoxystrobin and thiophanatemethyl in our isolates was based on point mutations in target genes, including G143A in $c y t b$ and F167Y in $\beta$-tubulin. As opposed to quantitative resistance, which may be multigenic and which is characterized by a small decrease in population sensitivity over time, qualitative resistance is typically conferred by point mutations in genes encoding target enzymes and is characterized by an immediate and significant shift toward resistance. For example, quantitative resistance to the QoI fungicide azoxystrobin was observed in A. solani isolates from potato fields throughout the Midwestern United States. After 3 years of applications, the mean $\mathrm{EC}_{50}$ values of pathogen populations changed from 0.038 to $2.3 \mu \mathrm{g} / \mathrm{ml}$ (Pasche et al. 2004). In contrast, qualitative resistance to the same chemical in A. alternata from California pistachio had $\mathrm{EC}_{50}$ values greater than $100 \mu \mathrm{g} / \mathrm{ml}$ (Ma et al. 2003a). Our data also reflect qualitative resistance with $\mathrm{EC}_{50}$ values for both azoxystrobin and thiophanate-methyl greater than $100 \mu \mathrm{g} / \mathrm{ml}$. Prior to this study, A. alternata from pistachio had been reported to develop qualitative resistance to dicarboximides, QoI, and SDHI (Avenot and Michailides 2007; Ma et al. 2003a; Ma and Michailides 2004).

Our genotypes resistant to three classes of fungicides only differed in their genetic basis of resistance to SDHI fungicides (Yang et al. 2015). The most common SDHI resistance genotypes, H277Y and H134R, were subjected to fitness analysis. Fitness was evaluated in terms of both "predicted" fitness (measurement of several components in individual isolates) and "realized" fitness (competition between sensitive and resistant isolates) (Karaoglanidis et al. 2011). Our investigation of fitness components revealed that genotypes H277Y and H134R didn't suffer obvious fitness penalties. For some parameters, including disease severity on peach and oxidative stress, genotype $\mathrm{H} 277 \mathrm{Y}$ even showed greater fitness than the boscalid-sensitive isolates. This mutation also appears to be a common and resilient resistance determinant in other pathogens. For example, the equivalent mutation was widespread in boscalid-resistant $B$. cinerea populations from strawberry and apple (Veloukas et al. 2011; Yin et al. 2011) and was not shown to affect fitness (Kim and Xiao 2011; Veloukas et al. 2014). A. alternata from pistachio with mutations in $s d h \mathrm{~B}, s d h \mathrm{C}$, and $s d h \mathrm{D}$ genes showed a high sensitivity to oxidative stress (Avenot et al. 2009). In our study, hypersensitivity to oxidative stress and other fitness penalties were observed only for genotype D123E, suggesting that this mutation imposed a fitness cost. This may partially explain the lower prevalence of this genotype in the field compared with the H277Y and H134R genotypes. Our results of predicted fitness, based on results from the two commonly found

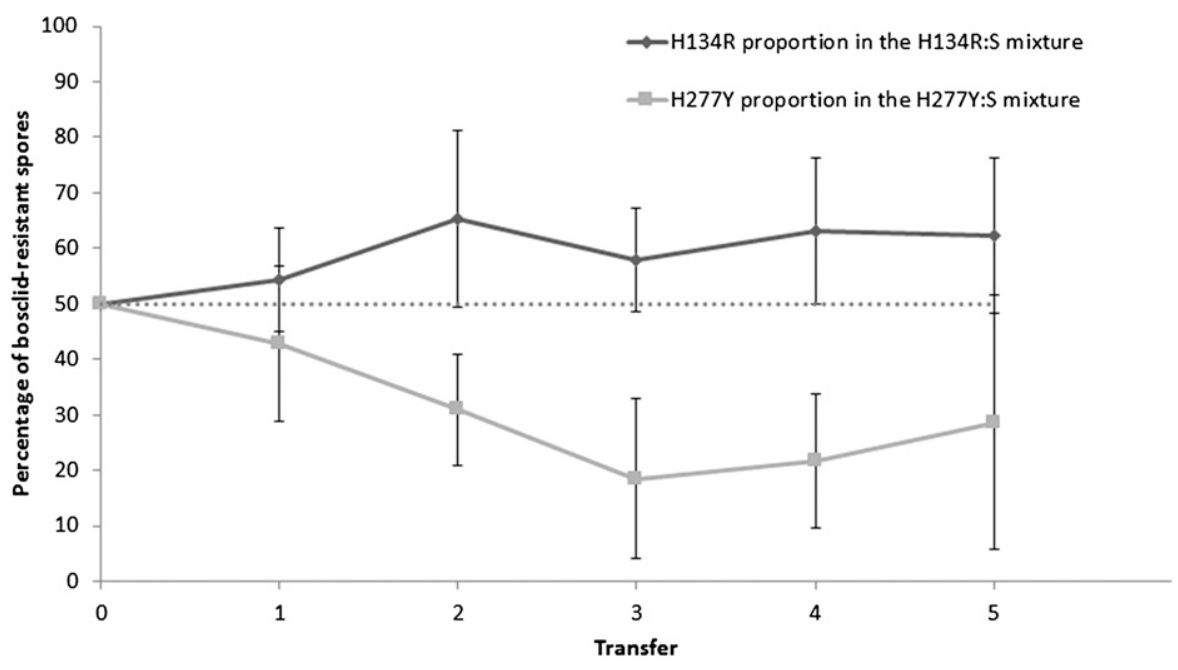

Fig. 4. Ratio of boscalid-resistant and boscalid-sensitive spores developing on canned peach fruit following five consecutive transfers. The dotted line at $y=50$ is used as a reference line to improve visualization. Error bars represent the standard deviation of the percentage of boscalid-resistant spores in the mixture after each transfer. 
resistant genotypes H134R and $\mathrm{H} 277 \mathrm{Y}$, are largely consistent with findings for A. alternata isolates from California pistachio (Avenot and Michailides 2007). Both studies show minor fitness penalties for the resistant isolates, suggesting that these genotypes probably compete successfully under field conditions.

In our study, results of predicted fitness agree with realized fitness. The competition analysis in the absence of fungicides indicated that genotypes H277Y and H134R successfully competed with boscalidsensitive isolates strains. These results are consistent with a study that analyzed the boscalid-resistant $\mathrm{H} 277 \mathrm{Y}$-equivalent genotype in $B$. cinerea (Lalève et al. 2014). However, another study documented competitive weaknesses of boscalid-resistant $B$. cinerea strains of the H277Y-quivalent SDHI-genotype (Kim and Xiao 2011; Veloukas et al. 2014). Depending on the pathogen studied, however, the same mutation may or may not be associated with fitness penalties (Karaoglanidis et al. 2011; Ma and Uddin 2009; Rallos et al. 2014).

The results of this study suggest that mixing or alternating chemical classes of fungicides for resistance management is now selecting for multifungicide resistance in primary and secondary pathogens of peach. Although these resistant populations are still rarely observed in the Southeast, independent emergence and movement from existing locations will eventually spread resistant genotypes under current management strategies. The lack of a penalty in fitness or competitive ability among the most prevalent, boscalid-resistant $A$. alternata genotypes implies that these genotypes will likely remain in the population, even in the absence of selection pressure. This development justifies a review of current resistance management practices. Alternatives to sole reliance on single-site fungicides may become more important and may include the development and use of cultivars less susceptible to disease, the increased use of multisite fungicides that do not select for resistance, stronger emphasis of cultural methods that decrease inoculum pressure, and further restriction of the number of applications of single-site fungicides per season.

\section{Acknowledgments}

This material is based upon work supported by NIFA United States Department of Agriculture under project number SC-1700501, the South Carolina Peach Council, and the South Carolina Specialty Block Grant 14-SCBGP-SC-0045. We thank K. P. Bryson for technical assistance and the South Carolina Peach Council for funding.

\section{Literature Cited}

Avenot, H., Morgan, D. P., and Michailides, T. J. 2008a. Resistance to pyraclostrobin, boscalid and multiple resistance to Pristine ${ }^{\circledR}$ (pyraclostrobin + boscalid) fungicide in Alternaria alternata causing Alternaria late blight of pistachios in California. Plant Pathol. 57:135-140.

Avenot, H., Sellam, A., Karaoglanidis, G., and Michailides, T. $2008 \mathrm{~b}$. Characterization of mutations in the iron-sulphur subunit of succinate dehydrogenase correlating with boscalid resistance in Alternaria alternata from California pistachio. Phytopathology 98:736-742.

Avenot, H., Sellam, A., and Michailides, T. 2009. Characterization of mutations in the membrane-anchored subunits AaSDHC and AaSDHD of succinate dehydrogenase from Alternaria alternata isolates conferring field resistance to the fungicide boscalid. Plant Pathol. 58:1134-1143.

Avenot, H. F., and Michailides, T. J. 2007. Resistance to boscalid fungicide in Alternaria alternata Isolates from pistachio in California. Plant Dis. 91: 1345-1350.

Baraldi, E., Mari, M., Chierici, E., Pondrelli, M., Bertolini, P., and Pratella, G. C. 2003. Studies on thiabendazole resistance of Penicillium expansum of pears: Pathogenic fitness and genetic characterization. Plant Pathol. 52:362-370.

Chapman, K. S., Sundin, G. W., and Beckerman, J. L. 2011. Identification of resistance to multiple fungicides in field populations of Venturia inaequalis. Plant Dis. 95:921-926.

Chen, F., Liu, X., Chen, S., Schnabel, E., and Schnabel, G. 2013a. Characterization of Monilinia fructicola strains resistant to both propiconazole and boscalid. Plant Dis. 97:645-651.
Chen, F., Liu, X., and Schnabel, G. 2013b. Field strains of Monilinia fructicola resistant to both MBC and DMI fungicides isolated from stone fruit orchards in the eastern United States. Plant Dis. 97:1063-1068.

Eckert, J. W., and Ogawa, J. M. 1988. The chemical control of postharvest diseases: Deciduous fruits, berries, vegetables and root/tuber crops. Annu. Rev. Phytopathol. 26:433-469.

Fernández-Ortuño, D., Chen, F., and Schnabel, G. 2012. Resistance to pyraclostrobin and boscalid in Botrytis cinerea isolates from strawberry fields in the Carolinas. Plant Dis. 96:1198-1203.

Hu, M., Grabke, A., Dowling, M. E., Holstein, H., and Schnabel, G. 2015. Resistance in Colletotrichum siamense from peach and blueberry to thiophanate-methyl and azoxystrobin. Plant Dis. 99:806-814.

Karaoglanidis, G. S., Luo, Y., and Michailides, T. J. 2011. Competitive Ability and Fitness of Alternaria alternata Isolates Resistant to QoI Fungicides. Plant Dis. 95:178-182.

Kim, Y. K., and Xiao, C. L. 2011. Stability and fitness of pyraclostrobin- and boscalid-resistant phenotypes in field isolates of Botrytis cinerea from apple. Phytopathology 101:1385-1391.

Köller, W., and Wilcox, W. 2001. Evidence for the predisposition of fungicideresistant isolates of Venturia inaequalis to a preferential selection for resistance to other fungicides. Phytopathology 91:776-781.

Lalève, A., Fillinger, S., and Walker, A. 2014. Fitness measurement reveals contrasting costs in homologous recombinant mutants of Botrytis cinered resistant to succinate dehydrogenase inhibitors. Fungal Genet. Biol. 67:24-36

Li, J., Katiyar, S. K., and Edlind, T. D. 1996. Site-directed mutagenesis of Saccharomyces cerevisiae $\beta$-tubulin: Interaction between residue 167 and benzimidazole compounds. FEBS Lett. 385:7-10.

Luo, C. X., and Schnabel, G. 2008. The cytochrome P450 lanosterol 14alphademethylase gene is a demethylation inhibitor fungicide resistance determinan in Monilinia fructicola field isolates from Georgia. Appl. Environ. Microbiol. 74:359-366.

Ma, B., and Uddin, W. 2009. Fitness and competitive ability of an azoxystrobinresistant G143A mutant of Magnaporthe oryzae from perennial ryegrass. Plant Dis. 93:1044-1049.

Ma, Z., Felts, D., and Michailides, T. J. 2003a. Resistance to azoxystrobin in Alternaria isolates from pistachio in California. Pestic. Biochem. Physiol. 77:66-74.

Ma, Z., and Michailides, T. J. 2004. Characterization of iprodione-resistant Alternaria isolates from pistachio in California. Pestic. Biochem. Physiol. 80:75-84.

Ma, Z., Yoshimura, M. A., and Michailides, T. J. 2003b. Identification and characterization of benzimidazole resistance in Monilinia fructicola from stone fruit orchards in California. Appl. Environ. Microbiol. 69:7145-7152.

Pasche, J. S., Wharam, C. M., and Gudmestad, N. C. 2004. Shift in sensitivity of Alternaria solani in response to QoI fungicides. Plant Dis. 88:181-187.

Pringle, A., and Taylor, J. W. 2002. The fitness of filamentous fungi. Trends Microbiol. 10:474-481

Qiu, J., Xu, J., Yu, J., Bi, C., Chen, C., and Zhou, M. 2011. Localisation of the benzimidazole fungicide binding site of Gibberella zeae $\beta 2$-tubulin studied by site-directed mutagenesis. Pest Manage. Sci. 67:191-198.

Rallos, L. E. E., Johnson, N. G., Schmale, D. G., Prussin, A. J., and Baudoin, A. B. 2014. Fitness of Erysiphe necator with G143A-based resistance to quinone outside inhibitors. Plant Dis. 98:1494-1502.

Thomidis, T., Michailides, T., and Exadaktylou, E. 2009. Contribution of pathogens to peach fruit rot in northern Greece and their sensitivity to iprodione, carbendazim, thiophanate-methyl and tebuconazole fungicides. J. Phytopathol. 157:194-200.

Vega, B., Liberti, D., Harmon, P. F., and Dewdney, M. M. 2012. A rapid resazurinbased microtiter assay to evaluate QoI sensitivity for Alternaria alternata isolates and their molecular characterization. Plant Dis. 96:1262-1270.

Veloukas, T., Kalogeropoulou, P., Markoglou, A. N., and Karaoglanidis, G. S. 2014. Fitness and competitive ability of Botrytis cinerea field isolates with dual resistance to SDHI and QoI fungicides, associated with several $s d h \mathrm{~B}$ and the cytb G143A mutations. Phytopathology 104:347-356.

Veloukas, T., Leroch, M., Hahn, M., and Karaoglanidis, G. S. 2011. Detection and molecular characterization of boscalid-resistant Botrytis cinerea isolates from strawberry. Plant Dis. 95:1302-1307.

Weber, R. W. S. 2011. Resistance of Botrytis cinerea to multiple fungicides in northern German small-fruit production. Plant Dis. 95:1263-1269.

Yang, J. H., Brannen, P. M., and Schnabel, G. 2015. Resistance in Alternaria alternata to SDHI fungicides causes rare disease outbreak in peach orchards. Plant Dis. 99:65-70.

Yin, Y. N., Kim, Y. K., and Xiao, C. L. 2011. Molecular characterization of boscalid resistance in field isolates of Botrytis cinerea from apple. Phytopathology 101:986-995 